\title{
A Single-Center Experience of Systemic Onset Juvenile Idiopathic Arthritis at a Tertiary Hospital in Jeddah, Saudi Arabia
}

\author{
Wallaa A. Garout, Mohammed A. Muzaffer \\ Department of Pediatrics, King Abdulaziz University Hospital, Jeddah, KSA \\ Email: dr.w.garout@gmail.com
}

Received 27 August 2014; revised 27 September 2014; accepted 13 October 2014

Copyright (C) 2014 by authors and Scientific Research Publishing Inc.

This work is licensed under the Creative Commons Attribution International License (CC BY). http://creativecommons.org/licenses/by/4.0/

(c) (i) Open Access

\section{Abstract}

Background and Objective: Systemic-onset juvenile idiopathic arthritis (JIA) is a major and prevalent subset of arthritis among children and it has a broad spectrum of clinical presentation, course and prognosis. This study described the clinical presentation of systemic-onset JIA in a Saudibased cohort. Methods: A retrospective chart review was performed of the medical records of children with systemic-onset JIA who were followed up at King Abdul Aziz University Hospital, Jeddah, between January 1997 and December 2013. Patients' files were reviewed for demographic, clinical, and paraclinical data, which were analyzed using the statistical Package for the Social Sciences. Results: We included 20 patients of both genders ( 8 boys and 12 girls). The mean age of disease onset was 7 (4.5) years. The most common presenting symptoms were fever (100\%), arthritis (100\%), and rash (55\%). Hepatomegaly (5\%), abdominal (5\%) and pulmonary manifestations (3\%) were less frequent manifestations. Most patients had high white blood cell counts (50\%), elevated erythrocyte sedimentation rates $(80 \%)$ and C-reactive protein levels $(90 \%)$. The interval between onset of symptoms and diagnosis was $9.4(12.5)$ weeks. Patients were treated with non-steroidal anti-inflammatory drugs, methotrexate, steroids, anti-tumor necrosis agents, and disease-modifying anti-rheumatic drugs. Bone marrow biopsy was conducted to exclude malignancy in $20 \%$ of the patients. Conclusion: Saudi children with systemic-onset JIA present with prolonged fever and arthritis (mainly oligoarticular rather than polyarticular). Physicians should be aware of the presentation of systemic-onset JIA in our setting in order to make prompt diagnosis and treatment decisions as early as possible. Carful follow-up of febrile patients is paramount to reaching the diagnosis early and initiating treatment.

\section{Keywords}

SO-JIA, Systemic Onset Juvenile Idiopathic Arthritis, Clinical Presentation, Saudi Arabia 


\section{Introduction}

In 1897, Sir George Fredrick Still described three patterns of arthritis in 19 patients [1] [2]. One of these three patterns was known as Still's disease, which is currently known as systemic-onset juvenile idiopathic arthritis (JIA) [3].

Systemic-onset JIA is classified as a subset of JIA, which constitutes $10 \%-15 \%$ of all JIA cases [4]. It is characterized by a spectrum of clinical presentation, which in the initial stage can be misleading to the physician and be easily misdiagnosed before the full picture of the disease becomes apparent [5]. Therefore its definition was supplanted by the International League of Associations for Rheumatology (ILAR). Diagnosis of systemiconset JIA requires the presence of quotidian fever in addition to arthritis, rash, lymphadenopathy, organomegaly, or serositis if disease onset occurs before the age of 16 years [1] [6] [7]. Recently, there was an emerging consensus that systemic JIA should be viewed as an auto-inflammatory syndrome [8].

The course of systemic onset JIA is variable. It can involve many organ systems, and disease activity changes with time [9]. Delays in diagnosis worsen outcome and increase disease morbidity [10]. Furthermore, extensive investigations, prolonged hospitalizations and treatments of patients with systemic-onset JIA have placed substantial cost on hospitals, health staff, and families of patients, which could be minimized by better understanding of the nature of the disease.

The purpose of this review was to describe the clinical presentation of systemic-onset JIA in a Saudi-based cohort. To the best of our knowledge, only one study were reported the clinical presentation of Saudi patients with systemic-onset JIA [10].

\section{Methods}

A retrospective chart review was performed of the medical records of all cases of systemic-onset JIA that were diagnosed at the Pediatric Department of King Abdulaziz University Hospital between January 1997 and December 2013. Patients were included provided they had a diagnosis of systemic JIA diagnosed as per the criteria of the ILAR (Table 1) [5]. Patients who had other conditions that may present with fever and arthritis, such as infections, malignancies, and other inflammatory diseases (Kawasaki disease and systemic lupus erythematosus) were excluded [4]. Permission to conduct the study was granted by the Biomedical Ethics Committee of King Abdulaziz University.

For all patients included in this study, we documented the following data: gender, age of presentation, family history, clinical manifestations, physical findings, laboratory data, results of imaging studies, treatment received, and complications.

\section{Statistical Analysis}

The data were entered and analyzed using the Statistical Package for the Social Sciences (SPSS Inc., Chicago, IL, US), version 20. Descriptive statistics were computed for all variables. Results are expressed as frequencies, percentages, means and (standard deviation (SD)).

\section{Table 1. Classification criteria for systemic-onset juvenile idiopathic arthritis.}

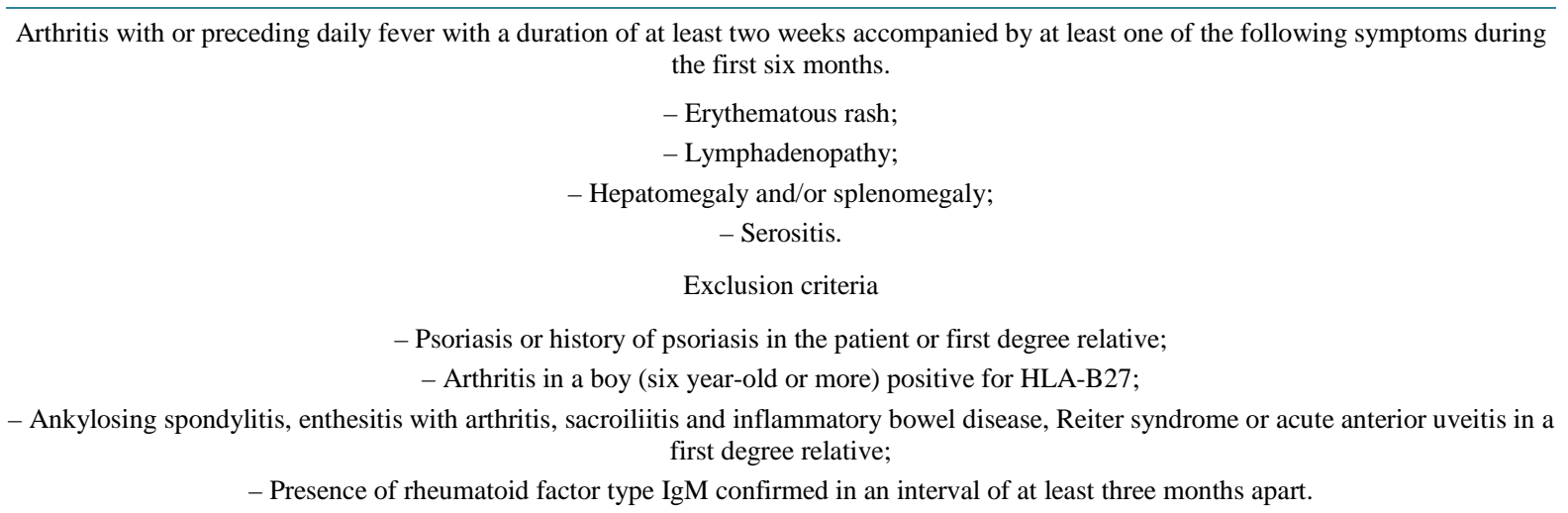




\section{Results}

We enrolled 20 patients aged 3 to 12 years (mean, 11.25 years). Females comprised a larger proportion of the sample ( $n=12 ; 60 \%)$. The mean (SD) age of disease onset was 7 (4.5) years (range, 112 years). The mean interval between the onset of symptoms and diagnosis was 9.2 (12.5) weeks (range, three weeks to one year).

The clinical manifestations of systemic-onset JIA in our patients are summarized in Table 2. Of the 20 patients, three females had a family history of rheumatic diseases. One patient had a sister with JIA; among the other two patients, one had a sister and a mother with JIA, while the other had a grandmother who was a rheumatoid arthritis patient.

The most commonly encountered features of systemic-onset JIA in our cohort were fever $(\mathrm{n}=20 ; 100 \%)$, rash $(n=11 ; 55 \%)$ and arthritis $(n=20 ; 100 \%)$. The average duration of fever in the sample was $5(10.6)$ months. Patients developed arthritis either early in the course of the disease or within a few weeks from the onset of fever. Most of the patients $(\mathrm{n}=16 ; 80 \%)$ had an oligoarticular pattern; only four patients (20\%) had a polyarticular pattern. The most frequently involved joints were the knees $(n=16 ; 80 \%)$, ankles $(n=14 ; 70 \%)$, and wrists $(n=8 ; 40 \%)$. Shoulder and interphalangeal joint involvement accounted for three cases (15\%) each.

Lymphadenopathy was detected in four patients (20\%). Cervical, inguinal, and axillary lymph node groups were involved. Splenomegaly was documented in four patients (20\%), while hepatomegaly was reported in one case (5\%). Four patients (20\%) had experienced pericarditis during the course of their illness.

Regarding the patients' laboratory results, hemoglobin levels were low for age in $85 \%$ of the patients (Table 3). Fifty percent of the patients had leukocytosis. Similarly, 50\% had thrombocytosis (mean, $518 \mathrm{~K} / \mu \mathrm{L}$ ); a

Table 2. Frequency of clinical manifestations of systemic onset juvenile idiopathic arthritis in the sample.

\begin{tabular}{|c|c|c|c|c|c|c|c|c|c|c|c|}
\hline Case & Sex & $\begin{array}{l}\text { Age of } \\
\text { Onset }\end{array}$ & $\begin{array}{c}\text { Duration from } \\
\text { Onset to } \\
\text { Diagnosis (wks) }\end{array}$ & $\begin{array}{l}\text { Family } \\
\text { History }\end{array}$ & $\begin{array}{c}\text { Fever } \\
\text { (month) }\end{array}$ & $\begin{array}{c}\text { Joint } \\
\text { Involvement }\end{array}$ & Rash & $\begin{array}{c}\text { Hepatom- } \\
\text { egaly }\end{array}$ & $\begin{array}{c}\text { Splenome- } \\
\text { galy }\end{array}$ & $\begin{array}{l}\text { Lymph } \\
\text { Nodes }\end{array}$ & Co-Morbidity \\
\hline 1 & Male & 11.0 & 48 & - & 48.00 & + & - & - & - & - & - \\
\hline 2 & Female & 5.0 & 3 & - & 0.75 & + & + & - & - & - & - \\
\hline 3 & Male & 13.0 & 12 & - & 3.00 & + & - & - & - & - & - \\
\hline 4 & Male & 13.0 & 4 & - & 0.75 & + & - & - & - & - & - \\
\hline 5 & Female & 1.0 & 16 & - & 0.50 & + & - & - & - & - & - \\
\hline 6 & Male & 1.5 & 5 & + & 0.75 & + & - & - & - & - & - \\
\hline 7 & Female & 10.0 & 40 & - & 7.00 & + & - & - & - & - & - \\
\hline 8 & Male & 7.0 & 4 & - & 0.54 & + & - & - & + & - & - \\
\hline 9 & Male & 2.0 & 3 & - & 0.54 & + & + & - & + & + & - \\
\hline 10 & Female & 10.0 & 4 & - & 0.50 & + & + & - & + & + & Pericarditis \\
\hline 11 & Female & 4.0 & 7 & - & 7.00 & + & + & - & - & + & - \\
\hline 12 & Female & 2.0 & 12 & + & 12.00 & + & + & + & + & - & - \\
\hline 13 & Female & 2.0 & 4 & + & 2.00 & + & + & - & - & - & - \\
\hline 14 & Female & 7.0 & 3 & - & 0.75 & + & + & - & - & - & - \\
\hline 15 & Male & 3.0 & 5 & - & 5.00 & + & - & - & - & - & - \\
\hline 16 & Male & 3.0 & 3 & - & 0.25 & + & + & - & + & + & Pericarditis \\
\hline 17 & Female & 15.0 & 2 & - & 0.50 & + & - & - & - & - & Pericarditis \\
\hline 18 & Female & 7.0 & 3 & - & 0.50 & + & + & - & - & - & Pericarditis \\
\hline 19 & Female & 8.0 & 6 & - & 6.00 & + & + & - & - & - & - \\
\hline 20 & Female & 12.0 & 3 & - & 2.00 & + & + & - & - & - & - \\
\hline
\end{tabular}


Table 3. Summary of the patients’ laboratory data.

\begin{tabular}{|c|c|c|c|c|c|c|c|c|c|c|c|c|c|c|c|}
\hline & 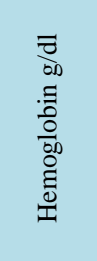 & 官 & 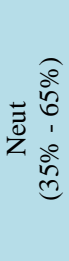 & 봉 & 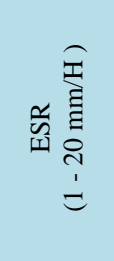 & 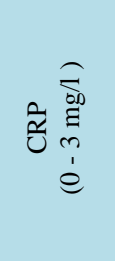 & 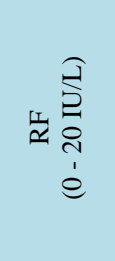 & 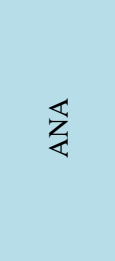 & 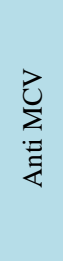 & 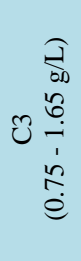 & 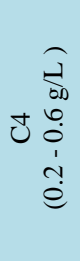 & 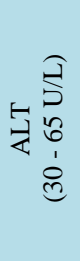 & 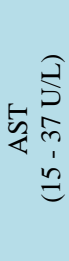 & 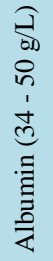 & 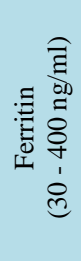 \\
\hline 1 & low & 5.8 & 54.2 & 590 & 78 & 119 & $<9.8$ & $\begin{array}{l}\text { mildly } \\
\text { positive }\end{array}$ & - & 1.9 & 0.231 & 21 & 21 & 21 & 873.8 \\
\hline 2 & low & 10.9 & 69.4 & 478 & 101 & 79.6 & $<9.6$ & negative & - & - & - & 51 & 26 & 24 & none \\
\hline 3 & low & 15.05 & 68 & 489 & 88 & 171 & 10.1 & negative & - & 2.22 & - & 7 & 26 & 26 & 14 \\
\hline 4 & low & 10.2 & 71.5 & 425 & 18 & 3.41 & 10 & not done & - & - & - & 22 & 35 & 35 & none \\
\hline 5 & normal & 6.03 & 43.5 & 345 & 6 & & - & negative & - & - & - & 19 & 38 & 38 & none \\
\hline 6 & low & 8.4 & 41.2 & 458 & 99 & 174 & $<7.3$ & negative & - & - & - & 29 & 25 & 25 & none \\
\hline 7 & low & 21.22 & 87.6 & 401 & 45 & 17.6 & 10.1 & negative & 14.7 & - & - & 16 & 36 & 36 & 311.8 \\
\hline 8 & low & 18 & 69 & 990 & 66 & 104 & 0 & - & - & - & - & 25 & 22 & 29 & 34.8 \\
\hline 9 & low & 21.5 & 17 & 597 & 117 & 222 & negative & $\begin{array}{l}\text { mildly } \\
\text { positive }\end{array}$ & - & 1.71 & 0.289 & 50 & 27 & 23 & none \\
\hline 10 & low & 27.25 & 94.3 & 352 & 79 & 298 & 10.6 & negative & - & 1.86 & 0.42 & 41 & 20 & 20 & 2000 \\
\hline 11 & low & 10.2 & 49 & 726 & 81 & 70 & - & negative & - & - & - & 19 & 26 & 26 & 505 \\
\hline 12 & low & 11.9 & 20.8 & 382 & 16 & 3.3 & $<8.7$ & negative & - & 1.71 & 0.266 & 29 & 33 & 33 & 24.5 \\
\hline 13 & low & 16.7 & 45 & 973 & 64 & 120 & - & negative & - & 1.16 & 0.193 & 38 & 36 & 28 & none \\
\hline 14 & low & 16.3 & 81.7 & 420 & 91 & 118 & 0 & negative & - & 0.76 & 0.46 & 16 & 27 & 27 & none \\
\hline 15 & low & 21.3 & 66.3 & 623 & 53 & 198 & 10.1 & negative & 22 & - & - & 19 & 33 & 33 & 736.6 \\
\hline 16 & low & 11.3 & 73 & 358 & 110 & 97.4 & $<9$ & negative & - & 1.78 & 0.374 & 192 & 31 & 19 & none \\
\hline 17 & low & 12 & 40 & 234 & 40 & 30 & negative & negative & - & - & - & 34 & 33 & 29 & none \\
\hline 18 & normal & 12 & 10 & 261 & 66 & 166 & negative & negative & - & 1.92 & 0.28 & 24 & 31 & 30 & none \\
\hline 19 & low & 14.17 & 85 & 334 & 99 & 164 & $<10$ & negative & - & 1.92 & 0.28 & 24 & 31 & 27 & 4295 \\
\hline 20 & normal & 18.3 & 81 & 922 & not done & not done & $<10$ & negative & - & 1.34 & 0.2 & 24 & 12 & 34 & none \\
\hline
\end{tabular}

Abbreviations: ALT: Alanine transaminase; ANA: Anti-nuclear antibody; AST: Aspartate aminotransferase; CRP: C-reactive protein; ESR: Erythrocyte sedimentation rate; MCV: Modified citrullinated vimentin; Neut: Neutrophils; PLT: Platelet; RF: Rheumatoid factor; WBC: White blood cell; -: Not done.

platelet count of $990 \mathrm{~K} / \mu \mathrm{L}$ was documented in one of the patients. Inflammatory markers were high in most patients, and up to 18 patients (90\%) had high levels of C-reactive protein (range, 3.4 to $298 \mathrm{mg} / \mathrm{L}$ ). The erythrocyte sedimentation rate was elevated in 16 patients (80\%; range, $6-117 \mathrm{~mm} /$ hour). Only one patient (5\%) had impaired liver function tests, while low albumin levels were documented in 13 patients (65\%). Ferritin levels were high in four (44.4\%) of the patients who did the test.

Antinuclear antibody titer was positive in two patients (10\%). Rheumatoid factor was negative in all the patients. Two patients who were tested for antibodies against a modified citrullinated vimentin (anti MCV) had positive results. There was no decrease in C3 and C4 levels in our cohort. The mean serum C3 concentration was $1.73(0.42) \mathrm{g} / \mathrm{dL}$ (reference range, $0.75-1.65 \mathrm{~g} / \mathrm{L}$ ), while mean C4 concentration was 0.30 (0.1) g/dL (reference range, $0.2-0.6 \mathrm{~g} / \mathrm{L})$.

Bone marrow aspiration was done to exclude malignancy in four patients (20\%).

Imaging studies, including magnetic resonance imaging (MRI), X-rays, and abdominal ultrasound were performed in six patients (30\%). One patient had multiple gallstones on ultrasound examination. Three patients 
showed evidence of joint damage, as demonstrated by the presence of lumbar lordosis, acetabular dysplasia, and severe narrowing of the hip joint on MRI and X-ray images.

Table 4 shows the frequency of complications of systemic-onset JIA in the cohort. One patient with the most severe disease course had limb discrepancy. Short stature complicated the course of disease in six patients (30\%). One patient had avascular necrosis. Three patients had psychological disorders. None of the patients had uveitis. Cushingoid features were documented in $40 \%$ of the patients.

Regarding treatment, all the patients received non-steroidal anti-inflammatory drugs (NSAIDs). Steroids were also prescribed in cases where NSAIDs were ineffective $(n=15 ; 75 \%)$. Methotrexate was also administered in 17 cases (85\%). Four patients received etanercept, an anti-tumor necrosis factor agent. Three patients were started on tocilizumab (a humanized anti-interleukin 6 receptor antibody). Six patients were treated with adalimumab (a tumor necrosis factor inhibitor).

\section{Discussion}

Systemic onset JIA is becoming more recognized among the Saudi society. Its diagnosis is based on clinical presentation, which makes it difficult for physicians to recognize the disease early. The variability and overlap of disease symptoms as well as lack of specific biomarkers pose an additional challenge to physicians [1].

In our study, we found that the main presenting symptoms, namely fever, rash, and arthritis, were similar to those reported in studies conducted abroad [1] [5] [6].The mean age of onset in our study is similar to 7.4 (5.5)

Table 4. Complications in patients with systemic onset juvenile idiopathic arthritis ${ }^{1}$.

\begin{tabular}{|c|c|c|c|c|c|c|c|c|c|c|c|}
\hline & $\begin{array}{l}\text { Articular } \\
\text { Deformity }\end{array}$ & $\begin{array}{c}\text { Articular } \\
\text { Damage }\end{array}$ & $\begin{array}{c}\text { Limb } \\
\text { Discrepancy }\end{array}$ & $\begin{array}{l}\text { Short } \\
\text { Stature }\end{array}$ & $\begin{array}{c}\text { Bone } \\
\text { Fracture }\end{array}$ & $\begin{array}{c}\text { Avascular } \\
\text { Necrosis }\end{array}$ & $\begin{array}{c}\text { Liver } \\
\text { Damage }\end{array}$ & Anemia & $\begin{array}{l}\text { Psychological } \\
\text { Disorders }\end{array}$ & Uveitis & $\begin{array}{l}\text { Cushingoid } \\
\text { Features }\end{array}$ \\
\hline 1 & + & + & - & + & - & - & - & - & - & - & - \\
\hline 2 & + & + & - & - & - & - & - & - & - & - & - \\
\hline 3 & - & - & - & - & - & - & - & - & - & - & + \\
\hline 4 & - & - & - & - & - & - & - & - & - & - & - \\
\hline 5 & - & - & - & - & - & - & - & - & - & - & - \\
\hline 6 & - & - & - & - & - & - & - & - & - & - & + \\
\hline 7 & - & - & - & - & - & - & - & - & - & - & - \\
\hline 8 & - & - & - & + & - & - & - & - & - & - & + \\
\hline 9 & - & - & - & - & - & - & - & - & - & - & - \\
\hline 10 & - & - & - & - & - & - & - & + & + & - & + \\
\hline 11 & - & + & - & + & - & - & - & + & + & - & + \\
\hline 12 & - & - & - & - & - & - & - & - & - & - & - \\
\hline 13 & - & - & - & + & - & - & - & + & - & - & + \\
\hline 14 & - & - & - & - & - & - & - & - & - & - & - \\
\hline 15 & - & - & - & + & + & - & - & + & - & - & + \\
\hline 16 & + & + & + & + & + & + & - & + & + & - & + \\
\hline 17 & - & - & - & - & - & - & - & + & - & - & - \\
\hline 18 & - & - & - & - & - & - & - & - & - & - & - \\
\hline 19 & - & - & - & - & - & - & - & + & - & - & - \\
\hline 20 & - & - & - & - & - & - & - & + & - & - & - \\
\hline
\end{tabular}

${ }^{1}$ Only cushingoid features and short stature are considered complications due to steroid use; all other complications could be caused by both the disease and steroids. Abbreviations: +: Positive; -: Negative. 
years reported by Yeh et al., who investigated the clinical investigations in 16 Taiwan children [1]. Another study conducted in Taiwan reported that the age of disease onset was 8.7 years. Contrary to our findings, other authors reported a lower age of disease onset. In the United States, the most common age of onset was reported to be two years [3], while another study conducted in Saudi Arabia found that patients were 5.3 years at disease onset [10].

The pattern of arthritis was predominantly oligoarticular in our patients (80\%). Tsai et al. [2] reported that the pattern of arthritis was oligoarticular in 50\% of their patients with systemic-onset JIA. In the literature [5] [6] [11] [12], however, joint involvement is predominantly polyarticular in systemic-onset JIA, contrary to our finding. In addition, while we found that most (60\%) of our patients were females, there was no predilection for sex in studies conducted aboard [5] [6]. The laboratory profile of our patients is similar to that reported by other authors [2] [5] [10], who documented leukocytosis, anemia, thrombocytosis, and elevated inflammatory markers in patients with systemic-onset JIA. Thrombocytosis is an important variable that should be determined early in the course of the disease, as it is a predictor of disease severity [13].

The prevalence of multiple diseases that could present initially with fever only might be an important factor in delaying the diagnosis in many patients. Most probably this cause lie behind the prolonged time between onset and diagnosis as many investigation are undertaken to exclude other differentials, for example, bone marrow aspiration, which is an invasive procedure, had to be performed in most of our patients to rule out malignancy. Further, the evolutional nature of disease symptoms contributes to this delay [3] [5] [6].

Systemic-onset JIA is a subset of JIA that is common in Saudi Arabia. In 1997, Baharbi et al. [10] described the clinical characteristic of JIA based on disease onset and found that $44 \%$ of the cases were of systemic onset.

Although our study provides an insight into the clinical presentation of systemic-onset JIA in our patients, its limitations cannot be overlooked. First, it is limited by its retrospective design. Second, it was a single-center hospital based study, and the findings cannot be therefore extrapolated to the population of Jeddah.

\section{Conclusion}

Overall, while our patients have arthritis with a predominantly oligoarticular pattern contrary to those in studies conducted abroad, the clinical presentation of the disease is similar. A high index of suspicion should be considered in order to identify patients with systemic-onset JIA and consequently initiate treatment as early as possible. Careful follow-up of febrile patients is paramount to making a prompt diagnosis and initiating treatment.

\section{References}

[1] Yeh, T.L., Huang, F.Y., Shyur, S.D., Chen, T.L., Lee, C.S. and Huang, D.T. (2010) Juvenile Idiopathic Arthritis Presenting with Prolonged Fever. Journal of Microbiology, Immunology and Infection, 43, 169-174. http://dx.doi.org/10.1016/S1684-1182(10)60027-8

[2] Tsai, H.Y., Lee, J.H., Yu, H.H., Wang, L.C., Yang, Y.H. and Chiang, B.L. (2012) Initial Manifestations and Clinical Course of Systemic Onset Juvenile Idiopathic Arthritis: A Ten-Year Retrospective Study. Journal of the Formosan Medical Association, 111, 542-549. http://dx.doi.org/10.1016/j.jfma.2011.06.013

[3] Gurion, R., Lehman, T.J. and Moorthy, L.N. (2012) Systemic Arthritis in Children: A Review of Clinical Presentation and Treatment. International Journal of Inflammation, 2012, Article ID: 271569. http://dx.doi.org/10.1155/2012/271569

[4] Cimaz, R., Von Scheven, A. and Hofer, M. (2012) Systemic-Onset Juvenile Idiopathic Arthritis: The Changing Life of a Rare Disease. Swiss Medical Weekly, 142, w13582.

[5] De Benedetti, F. and Schneider, R. (2010) Systemic Juvenile Idiopathic Arthritis. In: Textbook of Pediatric Rheumatology, 6th Edition, Saunders.

[6] Schneider, R. and Laxer, R.M. (2008) Chap. 3: Systemic Juvenile Idiopathic Arthritis. In: Cimaz, R. and Lehman, T.J.A., Eds., Handbook of Systemic Autoimmune Diseases (Series Editor: Asherson, R.A.). Vol. 6: Pediatrics in Systemic Autoimmune Diseases, 35-54.

[7] Cassidy, J.T., Levinson, J.E., Bass, J.C., Baum, J., Brewer Jr., E.J., Fink, C.W., Hanson, V., Jacobs, J.C., Masi, A.T., Schaller, J.G., et al. (1986) A Study of Classification Criteria for a Diagnosis of Juvenile Rheumatoid Arthritis. Arthritis \& Rheumatism, 29, 274-281. http://dx.doi.org/10.1002/art.1780290216

[8] Vastert, S.J., Kuis, W. and Grom, A.A. (2009) Systemic JIA: New Developments in the Understanding of the Pathophysiology and Therapy. Best Practice \& Research Clinical Rheumatology, 23, 655-664. http://dx.doi.org/10.1016/j.berh.2009.08.003 
[9] Batthish, M., Schneider, R., Ramanan, A.V., Achonu, C., Young, N.L. and Feldman, B.M. (2005) What Does “Active Disease” Mean? Patient and Parent Perceptions of Disease Activity in the Systemic Arthritis Form of Juvenile Idiopathic Arthritis (SO-JIA). Rheumatology (Oxford), 44, 796-799. http://dx.doi.org/10.1093/rheumatology/keh597

[10] Bahabri, S., Al-Sewairi, W., Al-Mazyad, A., Karrar, A., Al-Ballaa, S., El-Ramahai, K., et al. (1997) Juvenile Rheumatoid Arthritis: The Saudi Experience. Annals of Saudi Medicine, 17, 413-418.

[11] Singh-Grewal, D., Schneider, R., Bayer, N. and Feldman, B.M. (2006) Predictors of Disease Course and Remission in Systemic Juvenile Idiopathic Arthritis: Significance of Early Clinical and Laboratory Features. Arthritis \& Rheumatism, 54, 1595-1601. http://dx.doi.org/10.1002/art.21774

[12] Shishov, M., Henrickson, M., Burgos-Vargas, R., Rubio-Pérez, N., Baca, V., Romero-Feregrino, R, Solís-Vallejo, E., Huang, B., Grom, A.A. and Lovell, D.J. (2007) Systemic Features and Early Prognostic Factors in Hispanic and NonHispanic Children from the United States of America and Mexico with Systemic Juvenile Idiopathic Arthritis. Clinical and Experimental Rheumatology, 25, 907-914.

[13] Spiegel, L.R., Schneider, R., Lang, B.A., Birdi, N., Silverman, E.D., Laxer, R.M., et al. (2000) Early Predictors of Poor Functional Outcome in Systemic-Onset Juvenile Rheumatoid Arthritis: A Multicenter Cohort Study. Arthritis \& Rheumatism, 43, 2402-2409. http://dx.doi.org/10.1002/1529-0131(200011)43:11<2402::AID-ANR5>3.0.CO;2-C 
Scientific Research Publishing (SCIRP) is one of the largest Open Access journal publishers. It is currently publishing more than 200 open access, online, peer-reviewed journals covering a wide range of academic disciplines. SCIRP serves the worldwide academic communities and contributes to the progress and application of science with its publication.

Other selected journals from SCIRP are listed as below. Submit your manuscript to us via either submit@scirp.org or Online Submission Portal.
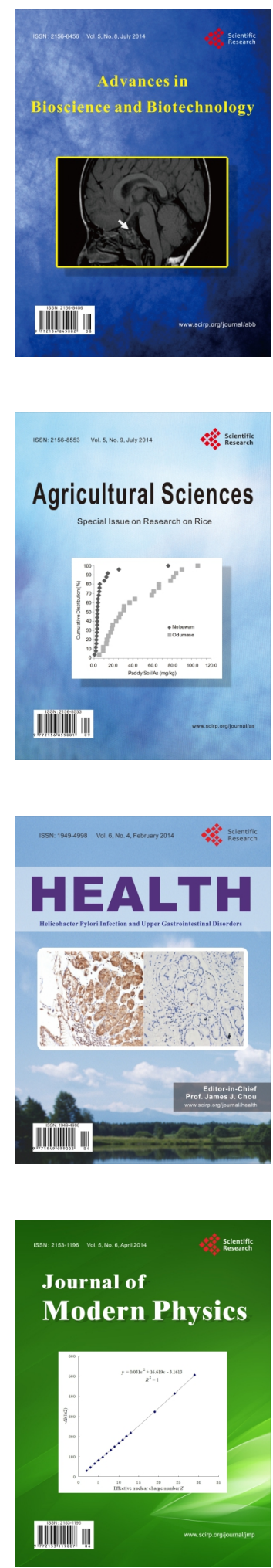
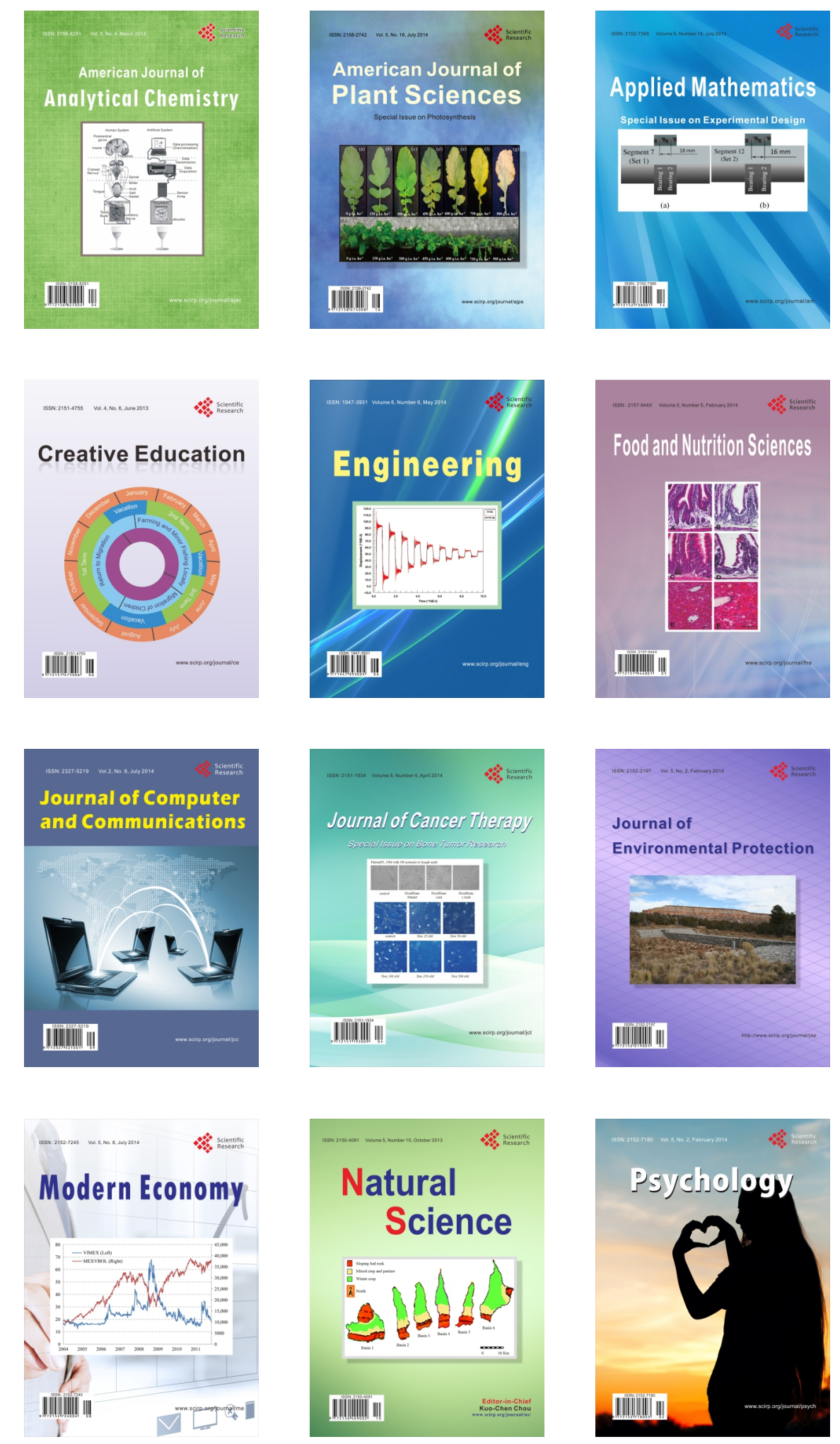